\title{
RRM1, TUBB3, TOP2A, CYP19A1, CYP2D6: Difference between mRNA and protein expression in predicting prognosis of breast cancer patients
}

\author{
YING-CHUN XU ${ }^{1,2^{*}}$, FENG-CHUN ZHANG ${ }^{3,4^{*}}$, JUN-JIAN LI $^{1}$, JIA-QI DAI ${ }^{2}$, QIANG LIU ${ }^{2}$, LEI TANG ${ }^{2}$, \\ YUE MA ${ }^{2}$, QI XU ${ }^{2}$, XIAO-LIN LIN ${ }^{2}$, HONG-BIN FAN ${ }^{2}$ and HONG-XIA WANG ${ }^{1}$ \\ ${ }^{1}$ Department of Oncology, Shanghai General Hospital, Shanghai Jiao Tong University School of Medicine, \\ Shanghai 200080; ${ }^{2}$ Department of Oncology, Renji Hospital, School of Medicine, Shanghai Jiao Tong University, \\ Shanghai 200127; ${ }^{3}$ Department of Oncology, Shanghai Ruijin Hospital, Shanghai Jiao Tong University \\ School of Medicine, Shanghai 200025; ${ }^{4}$ Department of Oncology, Suzhou Kowloon Hospital, \\ Shanghai Jiao Tong University School of Medicine, Suzhou, Jiangsu 215021, P.R. China
}

Received April 22, 2015; Accepted July 1, 2015

DOI: $10.3892 /$ or.2015.4183

\begin{abstract}
The study investigated the clinical significance of RRM1 (ribonucleoside reductase subunit M1), TUBB3 (tubulin- $\beta$-III), TOP2A (DNA topoisomerase II), CYP19A1 (cytochrome P450, family 19, subfamily A, polypeptide 1) and CYP2D6 (cytochrome P450, family 2, subfamily D, polypeptide 6) for the diagnosis and possible predictive roles in breast cancer. Tissue microarray detected the expression of RRM1, tubulin- $\beta$-III, Topo II $\alpha$, CYP19A1 and CYP2D6 protein in breast cancer tissue and tissue adjacent to tumors (TATs). In addition, a publically available tool, was used to assess the prognostic value of their gene expression in breast cancer (http://kmplot.com). Analysis for relapse-free survival (RFS), disease-free survival (DFS) and overall survival (OS) was performed. Cytoplasmic RRM1, tubulin- $\beta$-III, CYP19A1 and Topo II $\alpha$ staining were significantly higher in breast cancer tissues compared with TATs $(\mathrm{P}<0.050)$. Significant correlation occurred between RRM1 expression with pathological classification $(\mathrm{P}=0.018)$, lymph node involvement $(\mathrm{P}=0.035)$ and ER status $(\mathrm{P}=0.003)$. Tubulin- $\beta$-III and CYP2D6 expression correlated significantly with tumor grade $(\mathrm{P}=0.021$ for tubulin- $\beta$-III and $\mathrm{P}=0.029$ for $\mathrm{CYP} 2 \mathrm{D} 6$, respectively). Cox analysis showed that the protein expression of CYP2D6, CYP19A1, RRM1, Topo II $\alpha$ or tubulin- $\beta$-III was not an independent prognostic factor. A significant association occurred
\end{abstract}

Correspondence to: Dr Hong-Xia Wang, Department of Oncology, Shanghai General Hospital, School of Medicine, Shanghai Jiao Tong University, 100, Haining Road, Shanghai 200080, P.R. China

E-mail: whx365@126.com

${ }^{*}$ Contributed equally

Key words: breast cancer, prognosis, ribonucleoside reductase subunit M1, tubulin- $\beta$-III, DNA topoisomerase II, cytochrome P450, family 19 , subfamily A, polypeptide 1 , cytochrome P450, family 2 , subfamily D between RFS and TUBB3, TOP2A, CYP19A1, and CYP2D6 mRNA expression. With CYP19A1 $(\mathrm{P}<0.001)$ and CYP2D6 $(\mathrm{P}<0.001)$, a high expression was associated with good clinical outcome. Conversely, a low expression of TUBB3 $(\mathrm{P}<0.001)$ and TOP2A $(\mathrm{P}<0.001)$ was associated with good clinical outcome. TUBB3 $(\mathrm{P}=0.0004)$ and TOP $2 \mathrm{~A}(\mathrm{P}<0.001)$ were significant prognostic factors in predicting the patient $O S$. The expression of RRM1, tubulin- $\beta$-III, Topo II $\alpha$ and CYP19A1 in tumor tissues was significantly higher than that in TATs. TUBB3, TOP2A, CYP19A1 and CYP2D6 gene expression, but not protein expression, was associated with patient survival.

\section{Introduction}

Breast cancer is one of the most heterogeneous tumors, presenting various histologies, behaviors and outcomes (1-5). Patients with similar clinicopathological characteristics can have markedly different outcomes. The identification and extension of major prognostic determinants can facilitate the design of further clinical trials, aid in inter-trial comparisons and guide the counselling of individual patients.

Ribonucleoside reductase subunit M1 (RRM1), located on chromosome segment 11p15.5, is an essential enzyme that encodes the regulatory subunit of ribonucleotide reductase and catalyzes the reduction of ribonucleoside diphosphates to the corresponding deoxyribonucleotides, which is associated with the de novo DNA synthesis (6). RRM1 is involved in the regulation of cell proliferation, cell migration, cancer development and metastasis (7). It has been reported that RRM1 was a cell target of gemcitabine, a cytotoxic agent commonly used in the treatment of lung cancer, pancreatic carcinoma and breast cancer, which makes it a potentially suitable marker for clinical decision-making in tumor patients treated with gemcitabine-based chemotherapy (8). Tubulin- $\beta$-III, which is a major component of microtubules, can mediate cytotoxic effect of paclitaxel and is involved in various cell activities (9). Previous findings of tubulin- $\beta$-III focused on its function in the nervous system (10-11). However, it has been 
demonstrated that this tubulin isotype is expressed in proportion and associated with clinical resistance to taxane-based chemotherapy (12). As a member of the topoisomerase family, DNA topoisomerase II (Topo II) is an essential enzyme in DNA synthesis and meiotic division. DNA topoisomerases play an important role in DNA replication, recombination and transcription and have been identified as targets of numerous anticancer drugs. Topo II is highly expressed in many types of cancer cells. Breast cancer patients with HER-2/neu-positive tumors often benefit from topoisomerase II inhibitor-based chemotherapy (commonly doxorubicin or epirubicin) (13-14). Cytochrome P450 is important in the metabolism and transformation of endocrine agents in the mechanism-based treatment of estrogen receptor-positive mammary carcinoma (15). It has been demonstrated that cytochrome P450 is associated with the effects and side effects of endocrine pharmacotherapy. Polymorphisms of CYP19A1 (cytochrome P450, family 19, subfamily A, polypeptide 1) and phenotype of CYP2D6 (cytochrome P450, family 2, subfamily D, polypeptide 6) have become hot issues (16-17).

Concerning the role of RRM1, tubulin- $\beta$-III, Topo II $\alpha$, CYP19A1 and CYP2D6 in cancer treatment, a high-throughput detection of the expression of these markers in breast cancers by tissue microarray (TMA) was performed. Differential expression of these markers among the malignancies and tissue adjacent to tumors (TATs) was identified. Based on previous studies and the importance of these potential biomarkers, we examined the diagnostic roles of the genes according to gene phenotypes and investigated a possibly predictive role in breast cancer patients.

\section{Materials and methods}

Patients of tissue microarray. Formalin-fixed paraffinembedded tissue blocks containing invasive breast carcinomas and normal breast tissues were retrieved. The breast cancer TMA was created from 100 consecutive cases of primary breast cancer diagnosed between August 2004 and July 2007 at Renji Hospital (Shanghai, China). Histopathological and clinical findings were scored according to the tumor classification of the American Joint Committee on Cancer (AJCC)/Union for International Cancer Control (UICC) tumor staging system. Each patient was characterized by clinicopathological characteristics, including age, pre- or post-menopause, tumor location, pathological type, estrogen receptor (ER)/progesterone receptor (PR) status, HER-2 status, Ki67 expression and p53 expression. ER, PR, Ki67 and p53 expression were defined according to the new 1999 WHO/IASLC criteria, while the HER-2 overexpression (IHC) or gene amplification (FISH) was defined as 2013 ASCO/CAP criteria. These clinicopathological variables were obtained from patient files.

Prior to TMA construction, the breast cancer cases and tumor adjacent tissues, which represented normal breast tissue, were histopathologically re-evaluated on hematoxylin and eosin $(\mathrm{H} \& \mathrm{E})$-stained slides. Areas representative of cancer were then marked.

Tissue microarray. TMAs from breast cancer tissues and TATs with a distance of $2 \mathrm{~cm}$ from the tumor were constructed, as previously described (18). Two cores were obtained from each formalin-fixed, paraffin-embedded tumor and TAT sample by using punch cores that measured $1.0 \mathrm{~mm}$ at the greatest dimension from the non-necrotic area of tumor foci and TATs. Briefly, suitable areas for tissue retrieval were marked on standard H\&E sections, punched out of the paraffin block and inserted into a recipient block. The tissue arrayer was purchased from Beecher Instruments (Sun Prairie, WI, USA).

Immunohistochemistry. To determine the pattern of these markers in invasive human breast carcinomas in vivo, CYP2D6, CYP19A1, RRM1, Topo II $\alpha$ and tubulin- $\beta$-III expression was examined by the immunostaining of TMAs. The polyclonal antibody to RRM1 and monoclonal antibody to tubulin- $\beta$-III were obtained from Abcam (Cambridge, MA, USA). The monoclonal antibody Topo II $\alpha$ was purchased from Santa Cruz Biotechnology, Inc. (Santa Cruz, CA, USA). Polyclonal antibodies of CYP19A1 and CYP2D6 were commercially purchased from Lifespan (Providence, RI, USA) and Sigma (St. Louis, MO, USA), respectively.

Procedures were carried out as per the manufacturers' instructions. Sections were incubated with monoclonal antibodies against Topo II $\alpha$, CYP19A1, CYP2D6, RRM1 and tubulin- $\beta$-III. EnVision+ system and 3,3'-diaminobenzidine chromogen were applied (Dako, Copenhagen, Denmark).

Online database of breast cancer patients. The analysis for relapse-free survival (RFS), disease-free survival (DFS) and overall survival (OS) in the online database was performed in silico using the Kaplan-Meier Plotter of mRNA data developed by Gyorffy B (http://kmplot.com). The database was established using gene expression data and survival information on 2978 patients downloaded from the Gene Expression Omnibus (GEO) (Affymetrix HG-U133A and HG-U133+2 microarrays; Santa Clara, CA, USA) (19).

Statistical analysis. The analysis was performed using the SPSS software package (SPSS 16.0; Chicago, IL, USA). The correlation between CYP2D6, CYP19A1, RRM1, Topo II $\alpha$ and tubulin- $\beta$-III expression and clinicopathological characteristics was evaluated using the Chi-square test or Fisher's exact test. $\mathrm{P}<0.050$ denoted statistical significance.

Survival curves were estimated according to the KaplanMeier method. For each curve, the starting point was the date of diagnosis of breast cancer. Death from any cause was counted as an event in calculating survival time. For surviving patients, time was censored at the last available follow-up date.

\section{Results}

Expression of RRM1, tubulin- $\beta$-III, Topo II $\alpha, C Y P 19 A 1$ and CYP2D6 in breast cancer tissues and TATs. Clinicopathological characteristics of patients included in TMAs were summarized in Table I. The immunopositivity for RRM1, tubulin- $\beta$-III, Topo II $\alpha$, CYP19A1 and CYP2D6 was observed predominantly in the cytoplasm of breast cancer cells, which were homogeneous by buffy staining. The positively stained breast cancer cells were mostly round or oval, with an increased karyoplasmic ratio, and scattered or localized (Fig. 1). The tumorous or non-tumorous staining was semi-quantitatively scored by the intensity and percentage of positive staining. 
Table I. Clinicopathological characteristics of 100 patients with breast cancer.

\begin{tabular}{|c|c|c|}
\hline Characteristics & No. & Percentage \\
\hline \multicolumn{3}{|l|}{ Age (yr) } \\
\hline$<35$ & 2 & 2.0 \\
\hline$\geq 35$ & 98 & 98.0 \\
\hline \multicolumn{3}{|l|}{ Menses } \\
\hline Pre & 38 & 38.0 \\
\hline Post & 62 & 62.0 \\
\hline \multicolumn{3}{|l|}{ Tumor histology $\mathrm{y}^{\mathrm{a}}$} \\
\hline IDC & 78 & 78.0 \\
\hline ILC & 10 & 10.0 \\
\hline Mucinous & 7 & 7.0 \\
\hline Mixed and others & 5 & 5.0 \\
\hline \multicolumn{3}{|l|}{ Grade } \\
\hline High & 2 & 2.0 \\
\hline Moderate & 37 & 37.0 \\
\hline Low & 33 & 33.0 \\
\hline Missing & 28 & 28.0 \\
\hline \multicolumn{3}{|l|}{ Tumor size (cm) } \\
\hline$\leq 2$ & 37 & 37.0 \\
\hline $2.1-5$ & 49 & 49.0 \\
\hline$>5$ & 3 & 3.0 \\
\hline $\mathrm{CS}^{\mathrm{b}}$ & 1 & 1.0 \\
\hline Missing & 10 & 10.0 \\
\hline \multicolumn{3}{|l|}{ LN metastasis } \\
\hline No & 66 & 66.0 \\
\hline N1 & 14 & 14.0 \\
\hline $\mathrm{N} 2$ & 11 & 11.0 \\
\hline N3 & 6 & 6.0 \\
\hline Missing & 3 & 3.0 \\
\hline \multicolumn{3}{|l|}{ Stage } \\
\hline I & 28 & 28.0 \\
\hline II & 44 & 44.0 \\
\hline III & 18 & 18.0 \\
\hline Missing & 10 & 10.0 \\
\hline \multicolumn{3}{|l|}{ ER status } \\
\hline Positive & 64 & 64.0 \\
\hline Negative & 35 & 35.0 \\
\hline Missing & 1 & 1.0 \\
\hline \multicolumn{3}{|l|}{ PR status } \\
\hline Positive & 59 & 59.0 \\
\hline Negative & 39 & 39.0 \\
\hline Missing & 2 & 2.0 \\
\hline \multicolumn{3}{|l|}{ HER2 status } \\
\hline Positive & 30 & 30.0 \\
\hline Negative & 68 & 68.0 \\
\hline Missing & 2 & 2.0 \\
\hline
\end{tabular}

${ }^{\text {a} W o r l d ~ H e a l t h ~ O r g a n i z a t i o n ~ h i s t o l o g i c ~ c l a s s i f i c a t i o n ~ o f ~ b r e a s t ~ c a n c e r ; ~}$ $\mathrm{CS}^{\mathrm{b}}$, chest wall or skin invasion. IDC, invasive ductal carcinoma; ILC, invasive lobular carcinoma; UK, unknown.

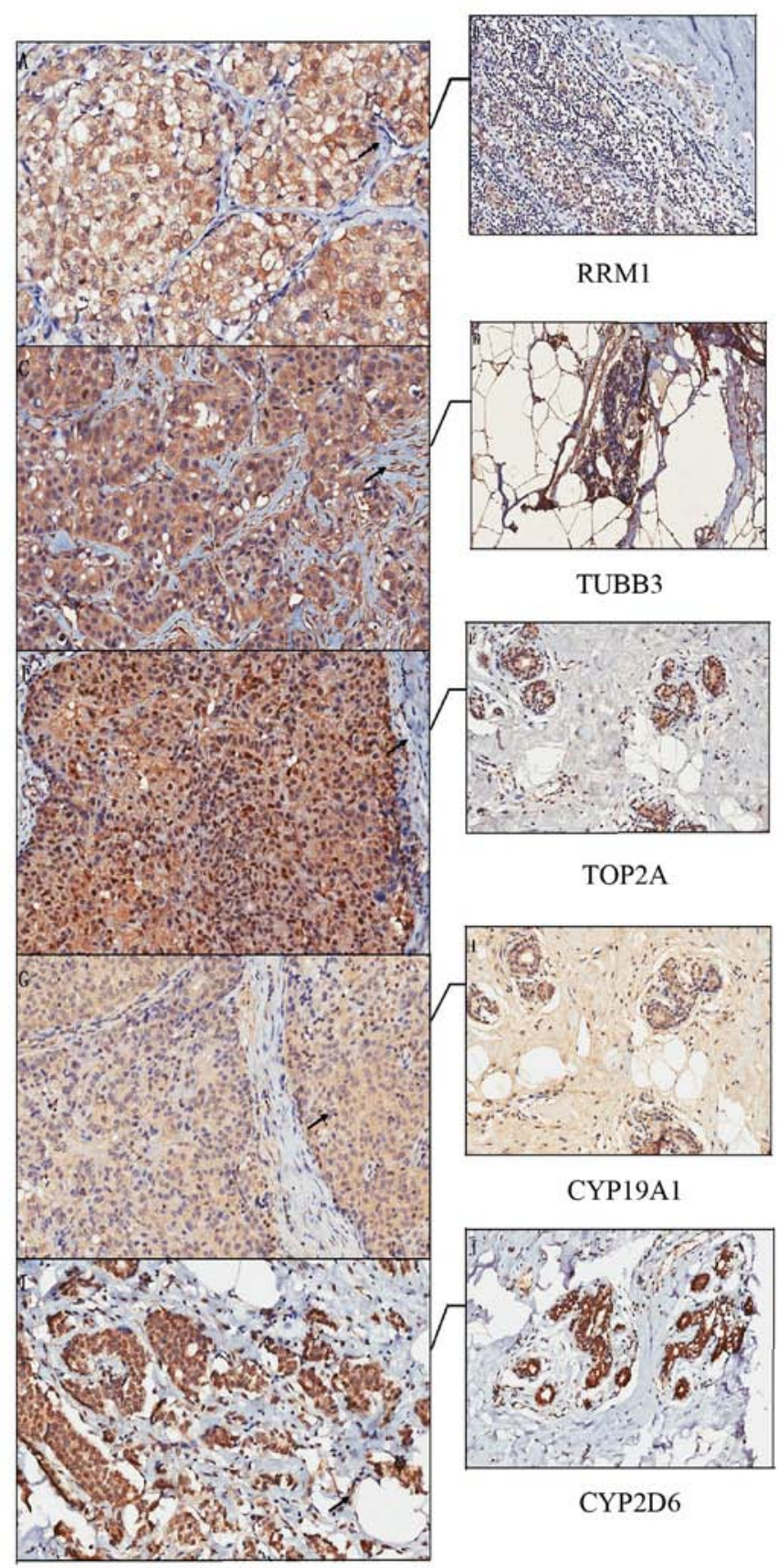

Figure 1. Immunopositivity for RRM1, tubulin- $\beta$-III, Topo II $\alpha$, CYP19A1 and CYP2D6. RRM1, ribonucleoside reductase subunit M1; Topo II $\alpha$, DNA topoisomerase II; CYP19A1, cytochrome P450, family 19, subfamily A, polypeptide 1; CYP2D6, cytochrome P450, family 2 , subfamily D, polypeptide 6 .

The results showed that the expression of RRM1, tubulin- $\beta$-III and Topo II $\alpha$ in tumor tissues was significantly higher than that in TATs. A statistically significant difference in cytoplasmic RRM1 staining was observed in tumor tissues when compared with TATs $(\mathrm{P}<0.001)$. Negative RRM1 staining was identified in $9.57 \%$ of tumors vs. $40.0 \%$ of TATs; weak staining, $35.11 \%$ in tumors vs. $58.18 \%$ in TATs; moderate staining, $36.17 \%$ in tumors vs. $1.82 \%$ in TATs; and strong staining, $19.15 \%$ in tumors vs. $0 \%$ in TATs. There were $87.23 \%$ tumors and $57.38 \%$ of TATs stained moderately and strongly by tubulin- $\beta$-III antibody $(\mathrm{P}<0.001)$. Negative tubulin- $\beta$-III staining was demonstrated in $2.04 \%$ of cancer 
Table II. Correlation between RRM1, TUBB3, CYP2D6, TOP2A, CYP19A1 and clinical variables in breast cancer.

Expression level

\begin{tabular}{lll} 
& \multicolumn{2}{c}{ Expression level } \\
\cline { 2 - 3 } Factors/group & Low $(0-1+) \quad$ High $(2+-3+)$ & P-value
\end{tabular}

RRM1

Tumor vs. normal

Tumor

TATs

Pathological

classification

$\begin{array}{lccc}\text { IDC } & 26(36.6) & 45(63.4) & 0.018^{\mathrm{a}} \\ \text { ILC } & 9(81.8) & 2(18.2) & \\ \text { MA } & 5(71.4) & 2(28.6) & \\ \text { Mixed \& others } & 2(40.0) & 3(60.0) & \\ \text { LN } & & \end{array}$

Positive

Negative

$21(35.0)$

39 (65.0)

$0.035^{\mathrm{a}}$

ER

Positive

$18(58.1)$

$13(41.9)$

Negative

34 (56.7)

8 (24.2)

$26(43.3)$

25 (75.8)

p53

Positive

$15(32.6)$

$31(67.4)$

Negative

$20(54.1)$

$17(45.9)$

TUBB3

Tumor vs. normal

Tumor

TATs

$12(12.8)$

26 (42.6)

$82(87.2)$

35 (57.4)

Grade

I

II

III

PR

\section{Positive}

Negative

CYP2D6

Tumor vs. normal

Tumor

TATs

13 (13.3)

$85(86.7)$

0.799

Grade

I

II

III

TOP2A

Tumor vs. normal

$\begin{array}{llll}\text { Tumor } & 33(34.0) & 64(66.0) & <0.001^{\mathrm{a}} \\ \text { TATs } & 47(79.7) & 12(20.3) & \\ \text { YP19A1 } & & & \\ \text { Tumor vs. normal } & & & \\ \text { Tumor } & 19(19.6) & 78(80.4) & 0.022 \\ \text { TATs } & 21(36.2) & 37(63.8) & \end{array}$

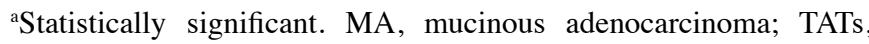
tissue adjacent to tumors. vs. $9.84 \%$ of TATs $(\mathrm{P}<0.001)$. A total of $65.97 \%$ of tumors and $20.33 \%$ of TATs showed moderate and strong staining by Topo II $\alpha$ antibody, with a statistically significant difference $(\mathrm{P}<0.001)$. The pattern of cytoplasmic CYP19A1 staining was significantly higher in breast cancer compared with TATs $(\mathrm{P}=0.022)$. No statistical difference was observed in the analysis of CYP2D6.

Correlation between the expression of RRM1, tubulin- $\beta$-III, Topo II $\alpha$, CYP19A1, CYP2D6 and clinical variables. A significant correlation was observed between RRM1 expression with pathological classification $(\mathrm{P}=0.018)$, lymph node involvement $(\mathrm{P}=0.035)$ and ER status $(\mathrm{P}=0.003)$ (Table II). Tubulin- $\beta$-III and CYP2D6 expression were correlated significantly with tumor grade $(\mathrm{P}=0.021$ for tubulin- $\beta$-III and $\mathrm{P}=0.029$ for CYP2D6, respectively). No correlation was obtained for the analysis between Topo II $\alpha$ or CYP19A1 expression with clinicopathological variables $(\mathrm{P}>0.050)$.

Univariate and multivariate survival analysis. To investigate the predictive ability of the five markers (RRM1, tubulin- $\beta$-III, Topo II $\alpha$, CYP19A1 and CYP2D6) for breast cancer patients, we performed a survival analysis using the Kaplan-Meier survival curve and log-rank test.

The results demonstrated that there was no significant association between DFS of breast cancer patients with CYP2D6 expression ( $\mathrm{P}=0.231)$, CYP19A1 expression $(\mathrm{P}=0.835)$, RRM1 expression $(\mathrm{P}=0.711)$, Topo $\mathrm{II} \alpha$ expression $(\mathrm{P}=0.568)$ and tubulin- $\beta$-III expression ( $\mathrm{P}=0.140$ ), respectively (Fig. 2$)$. The negative correlation was also obtained for the analysis of OS (CYP2D6,P=0.549; CYP19A1, P=0.666; RRM1,P=0.313, Topo $\mathrm{II} \alpha, \mathrm{P}=0.751$ and tubulin- $\beta$-III, $\mathrm{p}=0.333$, respectively) (Fig. 3). With respect to one-, two-, three- and five-year DFS rate or OS rate, there was also no significant difference obtained in patients with different protein expression status $(\mathrm{P}>0.050)$.

The Cox analysis showed that the CYP2D6, CYP19A1, RRM1, Topo IIa or tubulin- $\beta$-III protein expression was not an independent prognostic factor for breast cancer patients in this cohort.

Gene expression analysis for the predictive value of $C Y P 2 D 6$, CYP19A1, RRM1, TOP2A and TUBB3. A background database was established using gene expression ( $n=22,277$ genes) data from GEO (Affymetrix HG-U133A and HG-U133+2 microarrays), EGA and TCGA databases, including survival information of 2,978 breast cancer patients. The median RFS is 6.43 years. The gene expression analysis was undertaken to determine whether the gene expression profile of the five markers was associated with the survival of breast cancer patients. The centroid expression of these genes was applied as the threshold to classify the patients. Patients were classified into the high- and low-expression groups according to the median value of expression of each biomarker. The Kaplan-Meier Plotter identified a significant association between RFS and TUBB3, TOP2A, CYP19A1 and CYP2D6 expression. With respect to CYP19A1 $(\mathrm{P}<0.001)$ and CYP2D6 $(\mathrm{P}<0.001)$, the high expression was associated with good clinical outcomes. Conversely, the low expression of TUBB3 $(\mathrm{P}<0.001)$ and TOP2A $(\mathrm{P}<0.001)$ was associated with good clinical outcomes. TUBB3 and TOP2A were also significant prognostic factors in 

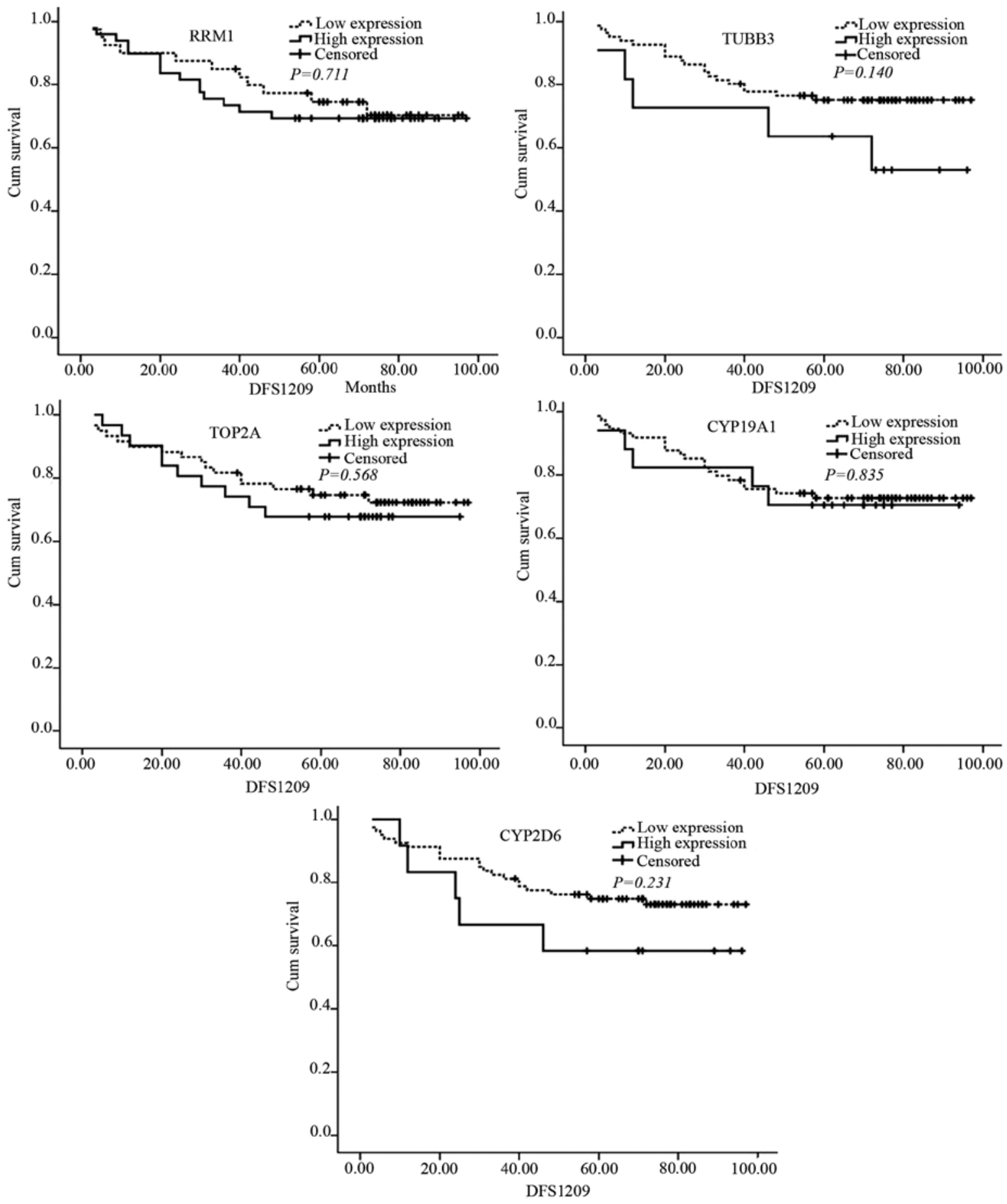

Figure 2. The relationship between RRM1, tubulin- $\beta$-III, Topo II $\alpha$, CYP19A1, CYP2D6 and DFS in a population of patients with resected breast cancer. RRM1, ribonucleoside reductase subunit M1; Topo II $\alpha$, DNA topoisomerase II; CYP19A1, cytochrome P450, family 19, subfamily A, polypeptide 1; CYP2D6, cytochrome P450, family 2, subfamily D, polypeptide 6; DFS, disease-free survival.

predicting the OS of breast cancer patients, with p-values of 0.0004 and $<0.001$, respectively (Fig. 4A-J).

Prediction value in different subtypes of breast cancer patients. The patients in the database were classified into eight subgroups: $\mathrm{ER}^{+}$group (1466/1942 patients, 75.5\%), ER' group (476/1942, 24.5\%), $\mathrm{LN}^{+}$group (613/2190 patients, $\left.28.0 \%\right)$, $\mathrm{LN}^{-}$group $(1577 / 2190,72.0 \%)$, luminal A ( $\left.\mathrm{n}=1410\right)$, luminal B $(\mathrm{n}=898)$, HER $^{+}(\mathrm{n}=175)$ and basal-like group $(\mathrm{n}=495)$, according to the gene expression profile and clinicopathological characteristics.

There was no significant association between RRM1 gene expression and RFS or OS in the study (Table III). Alterations in the expression level of TUBB3 were associated with RFS in $\mathrm{ER}^{+}, \mathrm{LN}^{-}$, luminal A and luminal B subgroups (Fig. 5A-C and $\mathrm{P}$ ). With respect to OS analysis, a statistical correlation was observed in luminal $\mathrm{B}$ and $\mathrm{HER} 2^{+}$-positive subgroups (Fig. 5Q-R). The upregulation of TUBB3 appeared 

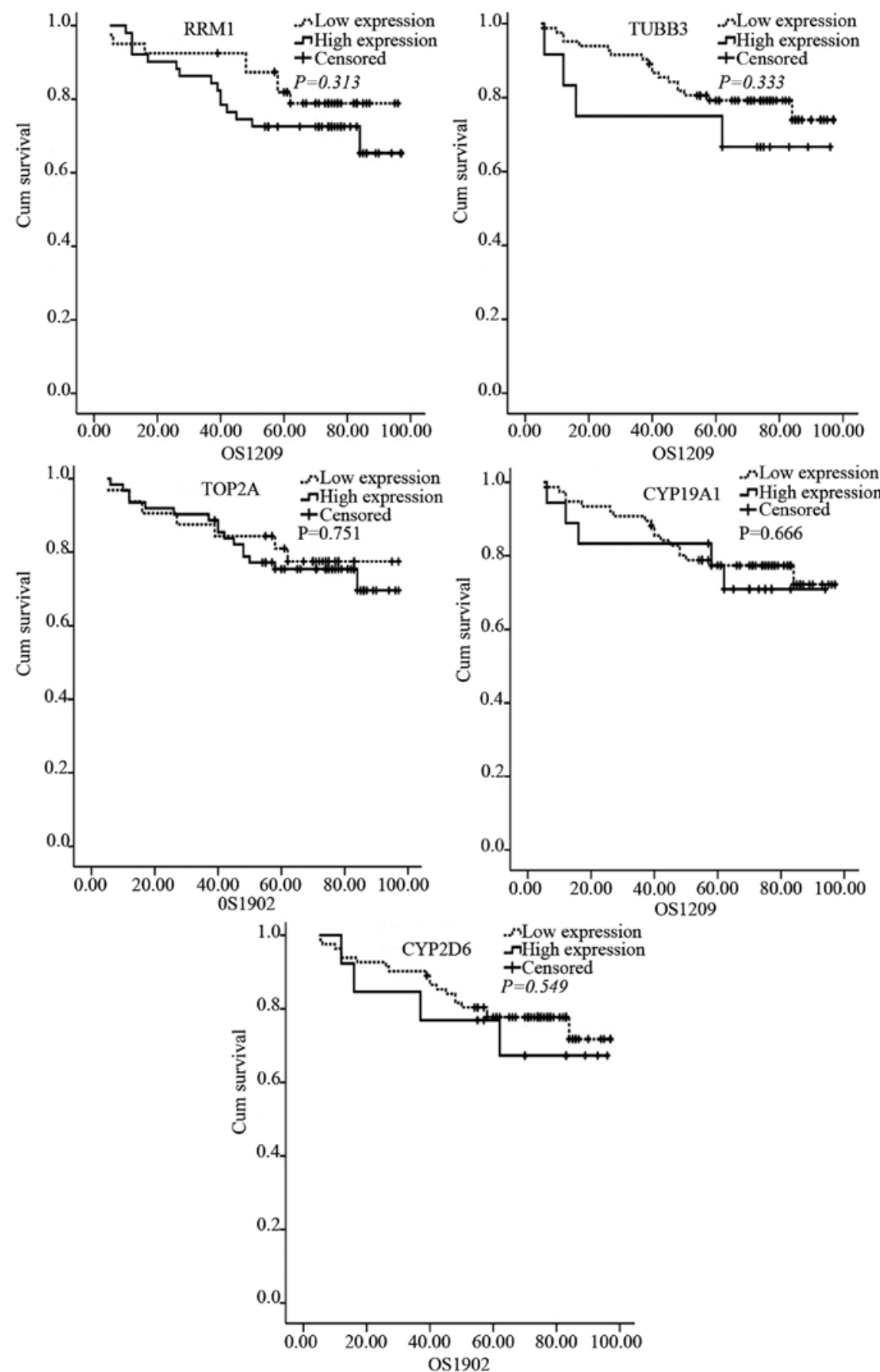

Figure 3. The relationship between RRM1, tubulin- $\beta$-III, Topo II $\alpha$, CYP19A1, CYP2D6 and OS. RRM1, ribonucleoside reductase subunit M1; Topo II $\alpha$, DNA topoisomerase II; CYP19A1, cytochrome P450, family 19, subfamily A, polypeptide 1; CYP2D6, cytochrome P450, family 2, subfamily D, polypeptide 6; OS, overall survival.

to be predictive of poor RFS and OS in these subgroup patients.

TOP2A expression was also a strong prognostic factor in patients with an ER-positive expression. The patients with lower expression of TOP2A had prolonged RFS and OS (HR 2.06, 95\% CI 1.68-2.51 and 2.94, 95\% CI 1. 80-4.80; Fig. 5D and G). Alterations of TOP2A expression were found to positively correlate with RFS in breast cancer patients regardless of lymph node status (Fig. 5E-F), and luminal A, luminal B and basal-like subgroups (Fig. 5S-U). In addition, we identified the prognostic value of TOP2A with OS in $\mathrm{LN}^{-}$, luminal A and luminal B subgroups, with poor prognostic effect for the high expression TOP2A (Fig. 5H-I and V).

A low expression of the CYP19A1 gene was correlated with poor RFS and OS in ER' patients (Fig. 5J and M), decreased RFS in HER2--negative molecular subtypes (Fig. 5K-L and W) and decreased $\mathrm{OS}$ in $\mathrm{LN}^{-}$patients (Fig. 5N). However, for HER2 overexpression subgroups, overexpression of the CYP19A1 gene was significantly associated with poor OS (Fig. 5O).

A low expression of the $C Y P 2 D 6$ gene was associated with unfavorable RFS in breast cancer patients, irrespective of the molecular subtype (Fig. 5X-Z and a). 

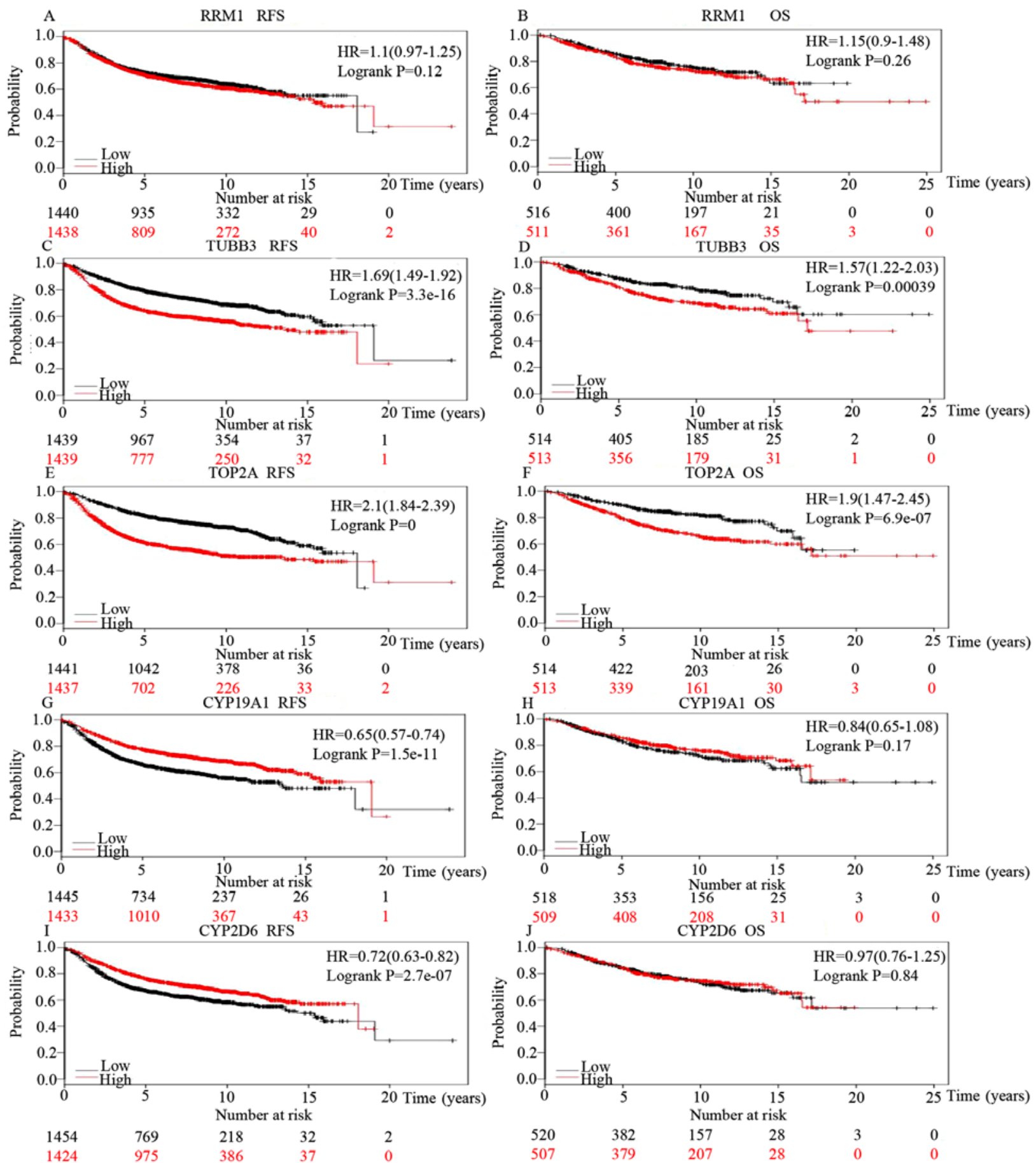

Figure 4. Kaplan-Meier survival curve: (4A, C, E, G and I) RFS and (4B, D, F, H and J) OS following breast cancer stratified by gene expression. RFS, relapse-free survival; OS, overall survival.

\section{Discussion}

Breast cancer is a significant health issue for women worldwide, with a lifetime risk of $12 \%$ and a risk of death of $5 \%$. Many histopathologic prognostic factors have been investigated extensively in breast cancer (20-21). The identification of additional prognostic markers in breast cancer remains crucial.

To the best of our knowledge, few published studies evaluating the prognostic value of RRM1, tubulin- $\beta$-III, Topo II $\alpha$, CYP19A1 and CYP2D6 in breast cancer are available.
The predictive impact of RRM1, tubulin- $\beta$-III, Topo II $\alpha$, CYP19A1 and CYP2D6 on breast cancer patients was assessed in the present study by IHC. The RRM1 haplotype showed an association with susceptibility to gemcitabine monotherapy in breast cancer patients (22). In the present study, 55.3\% of tumor tissues and $1.8 \%$ of TATs showed moderate and strong RRM1 expression $(\mathrm{P}<0.001)$. We also observed RRM1 expression is associated with pathological classification $(\mathrm{P}=0.018)$, ER status $(\mathrm{P}=0.003), \mathrm{p} 53$ status $(\mathrm{P}=0.049)$ and lymph node involvement $(\mathrm{P}=0.035)$. In some breast cancer cases, a high expression 
Table III. RFS and OS following breast cancer stratified by five gene expression and clinical pathological factors.

Genes

\begin{tabular}{|c|c|c|c|c|c|c|c|c|c|c|}
\hline \multirow[b]{2}{*}{ Subgroup } & \multicolumn{2}{|c|}{ RRM1 } & \multicolumn{2}{|c|}{ Tubulin- $\beta$-III } & \multicolumn{2}{|c|}{ TOP2A } & \multicolumn{2}{|c|}{ CYP19A1 } & \multicolumn{2}{|c|}{ CYP2D6 } \\
\hline & RFS & OS & RFS & OS & RFS & OS & RFS & OS & RFS & OS \\
\hline $\mathrm{ER}^{+}$ & 0.358 & 0.318 & $0.009^{\mathrm{a}}$ & 0.123 & $<0.001^{\mathrm{a}}$ & $<0.001^{\mathrm{a}}$ & 0.480 & 0.914 & 0.999 & 0.821 \\
\hline $\mathrm{ER}^{-}$ & 0.843 & 0.867 & 0.632 & 0.530 & 0.983 & 0.866 & $0.046^{\mathrm{a}}$ & 0.012 & 0.159 & 0.499 \\
\hline $\mathrm{LN}^{+}$ & 0.971 & 0.710 & 0.119 & 0.330 & $0.011^{\mathrm{a}}$ & 0.470 & 0.739 & 0.209 & 0.495 & 0.369 \\
\hline $\mathrm{LN}^{-}$ & 0.484 & 0.079 & $<0.001^{\mathrm{a}}$ & 0.110 & $<0.001^{\mathrm{a}}$ & $<0.001^{\mathrm{a}}$ & 0.242 & 0.033 & 0.640 & 0.779 \\
\hline Luminal A & 0.281 & 0.449 & $0.001^{\mathrm{a}}$ & 0.353 & $<0.001^{\mathrm{a}}$ & 0.001 & $0.004^{\mathrm{a}}$ & 0.609 & $0.004^{\mathrm{a}}$ & 0.680 \\
\hline Luminal B & 0.133 & 0.751 & $<0.001^{\mathrm{a}}$ & $0.003^{\mathrm{a}}$ & $<0.001^{\mathrm{a}}$ & $0.047^{\mathrm{a}}$ & $0.005^{\mathrm{a}}$ & 0.824 & $<0.001^{\mathrm{a}}$ & 0.974 \\
\hline HER $2^{+}$ & 0.104 & 0.115 & 0.448 & $0.028^{\mathrm{a}}$ & 0.515 & 0.898 & 0.256 & 0.028 & 0.049 & 0.403 \\
\hline Basal-like & 0.596 & 0.404 & 0.175 & 0.852 & $0.004^{\mathrm{a}}$ & 0.576 & $<0.001^{\mathrm{a}}$ & 0.141 & $<0.001^{\mathrm{a}}$ & 0.921 \\
\hline
\end{tabular}

P-value for the different mRNA expression of the five genes for RFS and OS in patients with different clinical pathological subtypes. RFS relapse-free survival.

of RRM1 was accompanied by EGFR overexpression (27). The cooperation of the two genes may be an important factor in carcinogenesis and the development of breast cancer. In the present study, no statistically significant differences were identified between RRM1 expression and survival of breast cancer patients by MTAs. With respect to whether RRM1 may be used as a predictive factor for the survival of breast cancer patients, the reports were inconsistent. However, no definite conclusion can be drawn based on published data. It has been reported that RRM1 expression at the protein level had no statistical association with clinical responsiveness to gemcitabine-based treatment (23). In addition to its role in gemcitabine resistance, RRM1 mRNA expression and genetic variants have been found to be associated with clinical outcomes of patients with cancer by genotyping detection (24-26). Patients with low RRM1 expression levels in peripheral blood had longer survival times than those with high RRM1 expression levels (16.95 vs. 12.76 months, log-rank 3.989, $\mathrm{P}=0.046$ ) (28). Studies have reported that there was no relationship between RRM1 expression and DFS, OS in adjuvant or advanced settings for BC patients according to immunohistochemical phenotypes $(8,27)$. However, in another study, Pesta et al found longer OS for NSCLC patients with adenocarcinoma had a higher expression of RRM1 in mRNA level $(\mathrm{P}=0.002)(29)$.

Our results have demonstrated that the expression of tubulin- $\beta$-III (moderate and strong staining, $87.23 \%$ vs. 57.38\%; $\mathrm{P}<0.001$ ) and Topo II $\alpha$ (moderate and strong staining, $65.97 \%$ vs. $20.33 \%$; $\mathrm{P}<0.001$ ) were significantly higher in tumor tissues than in TATs. Tubulin- $\beta$-III expression was correlated significantly with tumor grade $(\mathrm{P}=0.021)$. It has been generally accepted that the expression of tubulin- $\beta$-III and Topo II $\alpha$ are associated with the sensitivity of chemotherapy for cancer patients, in vitro or in clinical studies (30-32). Chemotherapy can lead to increased tubulin- $\beta$-III protein expression in tumor cells (33). Moreover, a high expression of tubulin- $\beta$-III is associated with sensitivity to chemotherapy and may act as a genetic marker to predict chemotherapy efficacy (34). The potential of tubulin- $\beta$-III as a treatment target or bio-marker for cancer patients has been investigated. For example, Ishida et al reported that tubulin- $\beta$-III was expressed in $50 \%$ of basal cell carcinomas (BCCs), predominantly the periphery of tumor nests. Tubulin- $\beta$-III is a potential candidate for inclusion in the panel of immunohistochemical markers to distinguish small BCCs from non-neoplastic hair buds (9). Uppala et al found that lycopene affected cell proliferation in MCF-7 breast cancer cells by modulating $\beta$-tubulin (35). The results from Zhao et al (36) showed that time to progression (TTP) was significantly longer in the low tubulin- $\beta$-III expression group $(\mathrm{P}=0.047)$ for recurrent/advanced breast cancer patients and tubulin- $\beta$-III can be used to predict the outcome of capecitabine in combination with taxanes.

Topo II $\alpha$ is a key enzyme in DNA replication and a target for many anticancer drugs, including doxorubicin, epirubicin and mitoxantrone. Cheng et al reported that Topo II inhibitor (B1) induced apoptosis and cell cycle G1 arrest in A549 lung adenocarcinoma cells (32). Immunohistochemical assessment of Topo II $\alpha$ expression showed median $14 \%$ of nuclei (range $2 \%$ to $62 \%$ ) was detected in all the tumors with highly variable inter- and intra-tumor nuclear reactivity. Our MTA results revealed that $65.97 \%$ of tumors and $20.33 \%$ of TATs showed moderate and strong staining by Topo II $\alpha$ antibody, with a statistical significant difference $(\mathrm{P}<0.001)$. Hellemans et al (37) reported that higher levels of Topo II $\alpha$ expression were strongly associated with a higher tumor grade, larger tumor size, nodal involvement and presence of distant metastases at diagnosis. However, the present study showed that no marked correlation was obtained for the analysis between Topo II $\alpha$ with clinicopathological variables $(\mathrm{P}>0.050)$. TOP $2 \mathrm{~A}$ gene amplification was reported to be a favorable prognostic marker in HER2 ${ }^{+}$metastatic breast cancer patients treated with trastuzumab (38). These reports showed that Topo II $\alpha$ is important in cell generation/apoptosis and can be considered a predictive marker in breast cancer patients.

The cytochrome P450 proteins are monooxygenases that catalyze many reactions involved in drug metabolism. In the present study, the pattern of cytoplasmic CYP19A1 
A TUBB3 RFS ER+

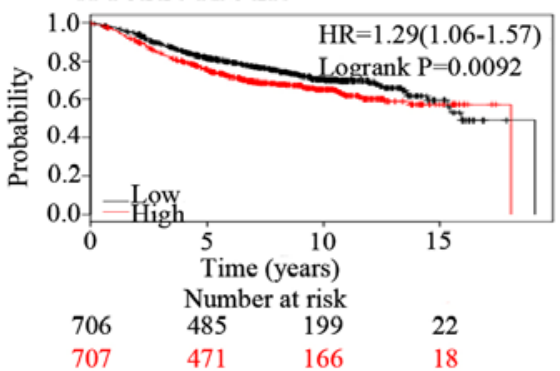

D TOP2A RFS ER+

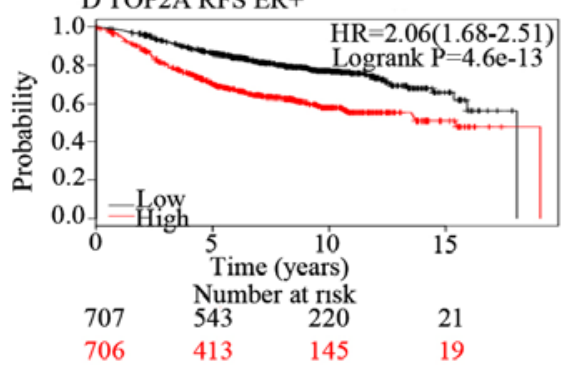

G TOP2A OS ER+

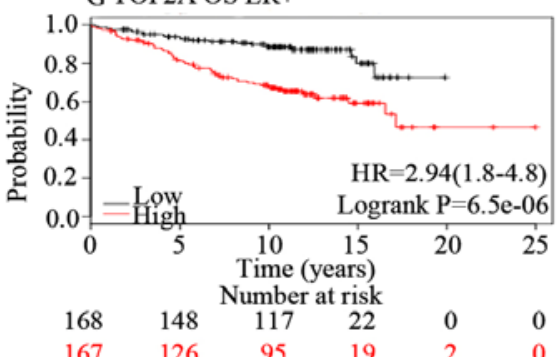

J CYP19A1 RFS ER-

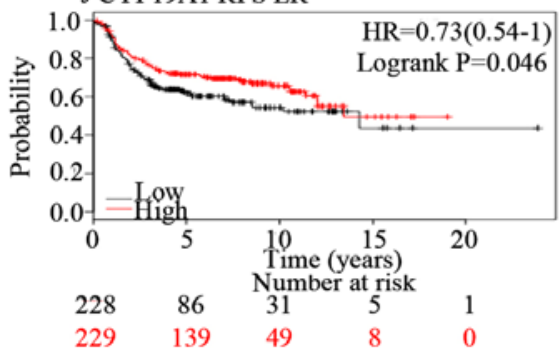

M CYP19A1 OS ER-

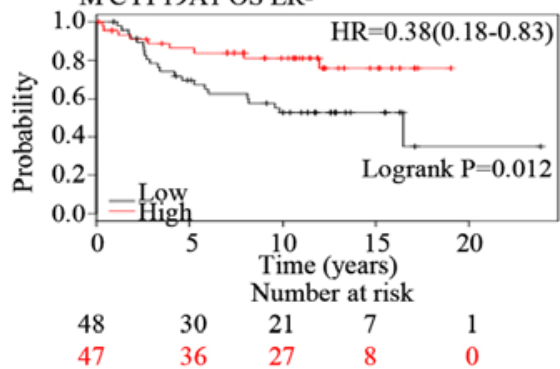

B TUBB3 RFS LN-
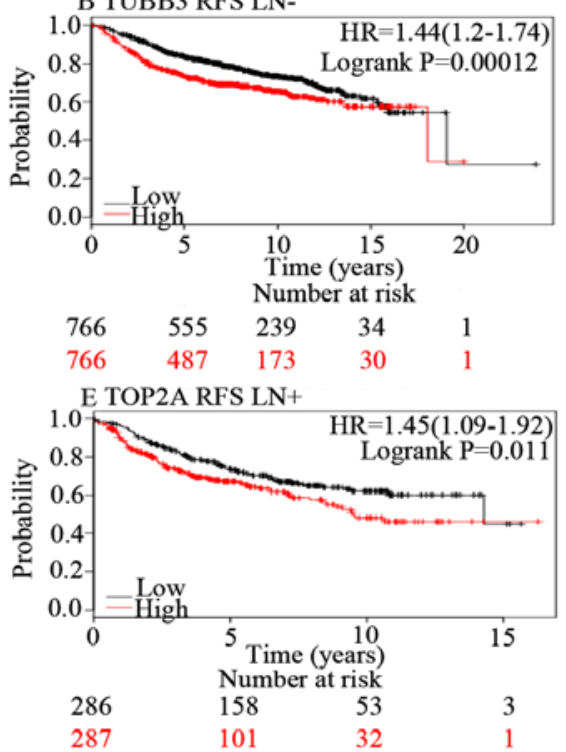

(10)

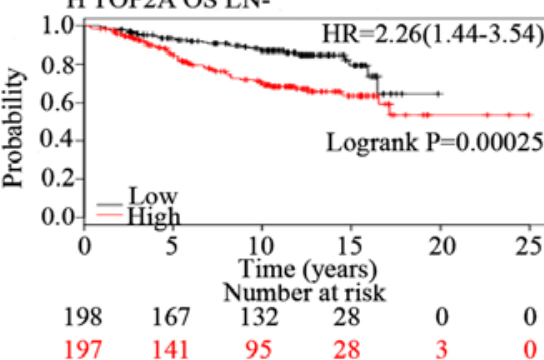

K CYP19A1 RFS Lumina1a

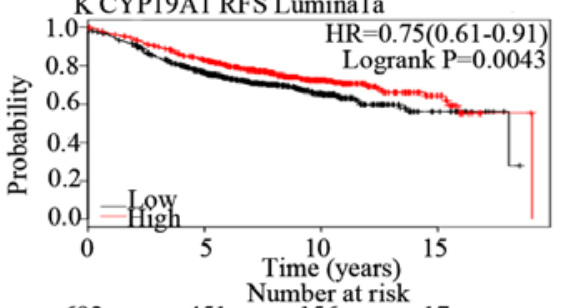

$692 \quad 451 \begin{gathered}\text { Number at risk } \\ 156\end{gathered}$

$\begin{array}{llll}678 & 524 & 207 & 31\end{array}$

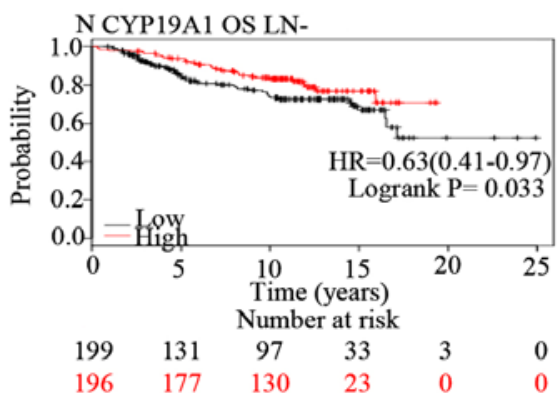

C TUBB3 RFS Lumian1A

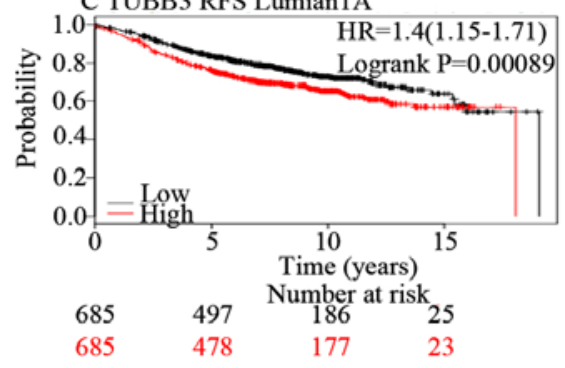

F TOP2A RFS LN-

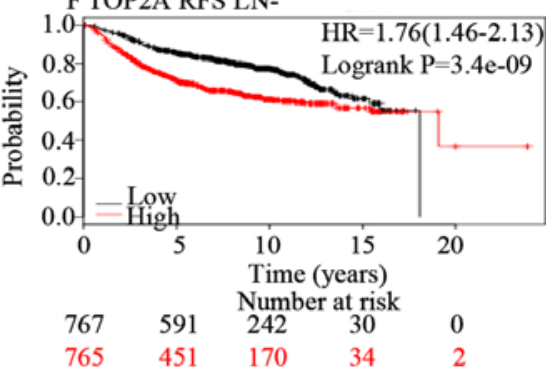

I TOP2A OS Lumina1A
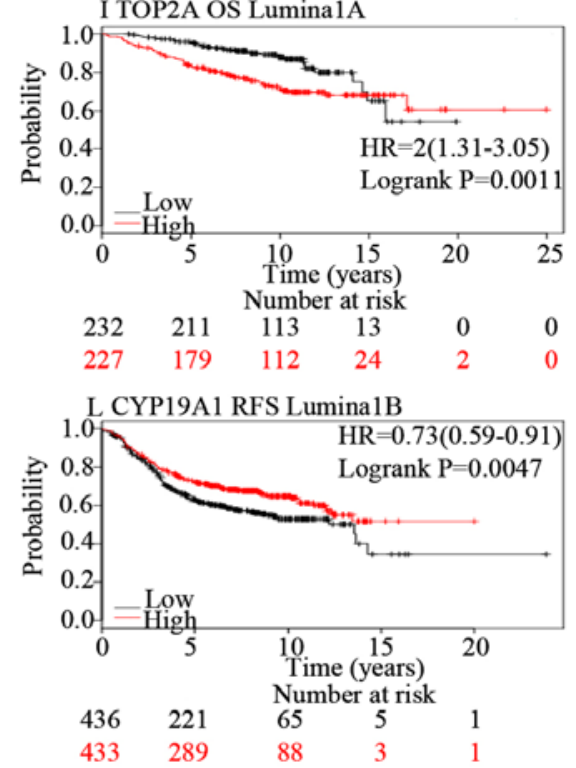

O CYP19A1 OS HER-2

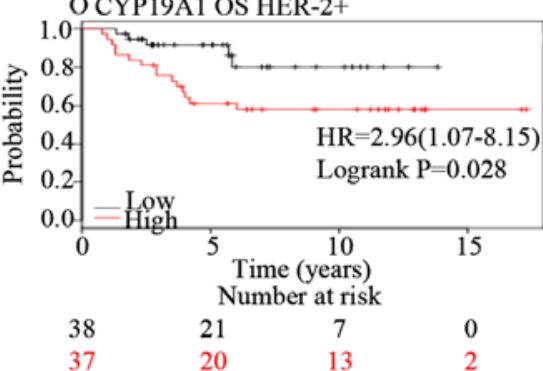

Figure 5. (A-O) Kaplan-Meier survival curve: predictive value for OS and RFS in different subgroups of breast cancer patients. OS, overall survival; RFS, relapse-free survival.

staining was significantly higher in breast cancer compared with TATs $(\mathrm{P}=0.022)$. No statistical difference was observed in the analysis of CYP2D6. With respect to CYP19A1 and CYP2D6, there have been novel findings concerning CYP19A1 (located on chromosome 15) and CYP2D6 (located on chromosome 22) in recent years. A number of studies have utilized candidate approaches to assess the role of variants in gene-encoding enzymes important in aromatase inhibitor metabolism, notably the impact of CYP19A1 (aromatase) and CYP2D6 phenotype on the effectiveness and the degree of endocrine symptoms associated with tamoxifen $(16,39)$. Additionally, CY P2D6 activity has been proven to be associated with poor treatment outcomes, in terms of increased risk of recurrence and shorter recurrence-free survival (40). In the present study, the pattern of cytoplasmic CYP19A1 staining was significantly higher in breast cancer compared 

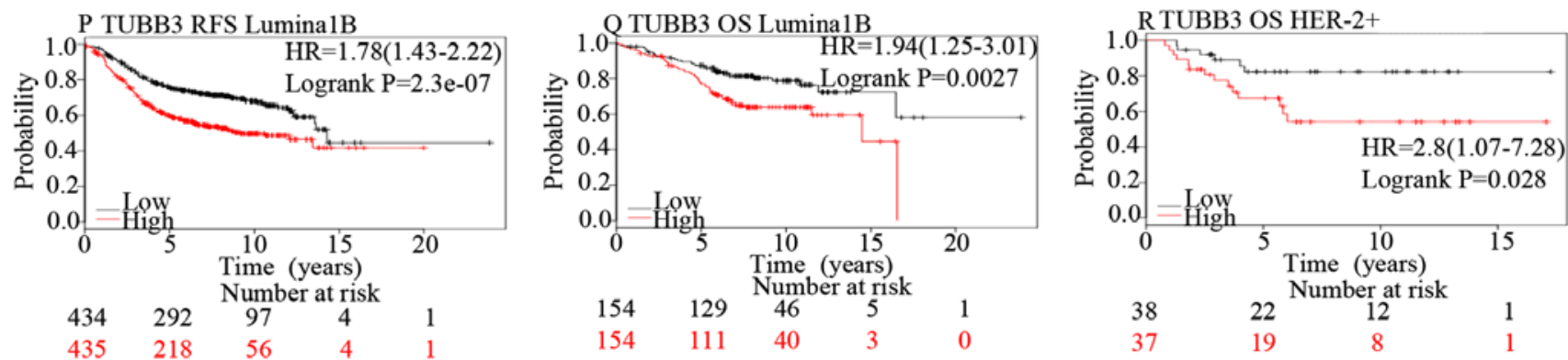

S TOP2A RFS Lumina1A
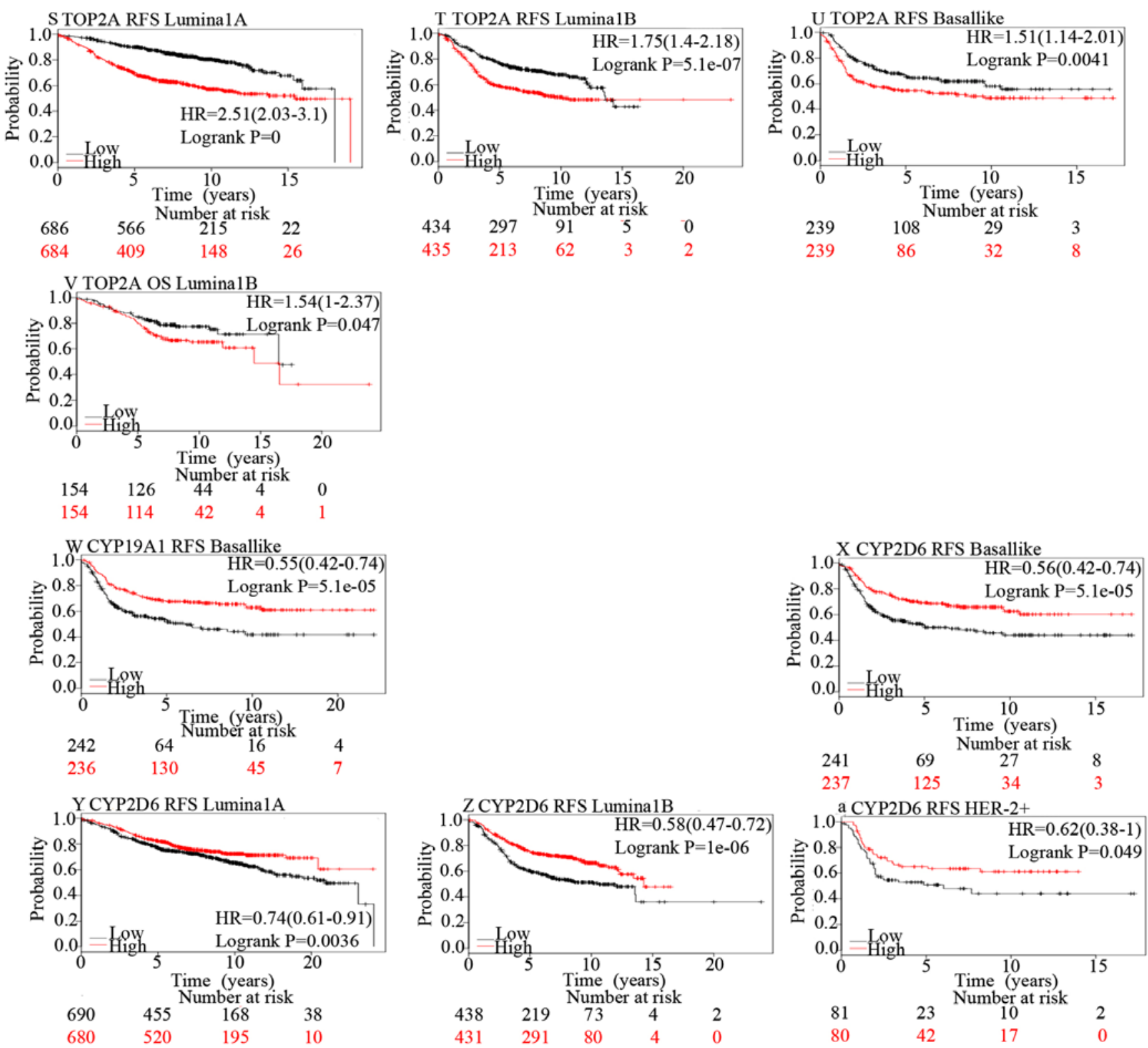

Figure 5. Continued. (P-a) Kaplan-Meier survival curve: predictive value for OS and RFS in different subgroups of breast cancer patients. OS, overall survival; RFS, relapse-free survival.

with TATs $(\mathrm{P}=0.022)$. No statistical difference was observed in the analysis of CYP2D6. A significant correlation was observed between CYP2D6 expression and grade of tumor cells $(\mathrm{P}=0.029)$. In the TMAs testing, no significant association between DFS or OS with CYP2D6 expression $(\mathrm{P}>0.050)$ and CYP19A1 expression $(\mathrm{P}>0.050)$ was observed. The Cox analysis showed that the CYP2D6, CYP19A1 and Topo II $\alpha$ protein expression were not independent prognostic factors for breast cancer patients in this cohort.

The gene microarray database analysis was employed to analyze the corresponding gene expression of these biomarkers to obtain insight into factors that may affect prognosis in breast cancer patients. The results showed that a significant association between RFS and TUBB3, TOP2A, 
CYP19A1 and CYP2D6 expression was observed. TUBB3 and TOP2A were also significant prognostic factors in predicting the OS of breast cancer patients, with p-values 0.0004 and $<0.001$, respectively. The findings are further supported by the lack of correlation between transcript and protein identified (41).

In the subgroup analysis, the upregulation of tubulin- $\beta$-III gene expression appeared to be predictive of poor RFS in $\mathrm{ER}^{+}, \mathrm{LN}^{-}$, luminal A and luminal $\mathrm{B}$ subgroups and poor OS in luminal B and HER 2 ${ }^{+}$subgroups. To the best of our knowledge, the results for the first time, provide further evidence that tubulin- $\beta$-III gene expression, but not the protein level, have a significant impact on the prognosis of breast cancer. These results are consistent with those of Vilmar et al. Statistically significant differences were reported by those authors for the prediction value of tubulin- $\beta$-III on OS in patients by IHC testing (18.5 vs. 11.10 months, $\mathrm{P}=0.027$ ), while this was not the case for RT-qPCR testing (41). The online database for TOP2A expression analysis indicated that TOP2A gene expression was positively correlated with RFS and OS in breast cancer patients in different subgroups stratified by ER, LN status and the molecular subtype. This result shows the potential of the TOP $2 \mathrm{~A}$ gene but not Topo II $\alpha$ protein as a prognostic factor. A low expression of the CYP19A1 gene was correlated with poor RFS in ER and HER2-negative molecular subtypes and decreased OS in $\mathrm{ER}^{-}$and $\mathrm{LN}^{-}$patients. However, for HER2 overexpression subgroups, the overexpression of the CYP19Al gene was significantly associated with poor OS. A low expression of the CYP2D6 gene was associated with unfavorable RFS in all of the breast cancer molecular subtypes.

In summary, we have identified relevant markers at the mRNA level, albeit not at the protein level. This finding is most likely due to the largely different sample sizes: 100 cases for protein analysis and 2,978 cases for mRNA analysis. To allow a meaningful interpretation of the data, the number of cases in the protein analysis needs to be increased in future studies.

In conclusion, the expression of RRM1, tubulin- $\beta$-III, Topo II $\alpha$ and CYP19A1 in tumor tissues was significantly higher than that in TATs, according to the immunohistochemical phenotypes. TUBB3, TOP2A, CYP19A1 and CYP2D6 gene expression, albeit not the protein expression, were associated with survival of breast cancer patients.

\section{Acknowledgements}

This study was supported by the National Natural Science Funds (no. 81102015 and 81301858), the Shanghai Pujiang Program (no. 11PJ1406500), the National Program on Key Basic Research Project (973 Program; no. 2013CB967201) and the Special Funds for Technological Innovation of Shanghai Jiaotong University (no. YG2012MS46).

\section{References}

1. Soerjomataram I, Louwman MW, Ribot JG, Roukema JA and Coebergh JW: An overview of prognostic factors for long-term survivors of breast cancer. Breast Cancer Res Treat 107: 309-330, 2008.

2. Wang H, Huang M, Zhang DY and Zhang F: Global profiling of signaling networks: Study of breast cancer stem cells and potential regulation. Oncologist 16: 966-979, 2011.
3. Wang H,Zhang F, Ye F, Ma Y and Zhang DY: The effect of Coptis chinensis on the signaling network in the squamous carcinoma cells. Front Biosci (Elite Ed) 3: 326-340, 2011.

4. Zhang F, Song C, Ma Y, Tang L, Xu Y and Wang H: Effect of fibroblasts on breast cancer cell mammosphere formation and regulation of stem cell-related gene expression. Int J Mol Med 28: 365-371, 2011.

5. Xu YC, Wang HX, Tang L, Ma Y and Zhang FC: A systematic review of vinorelbine for the treatment of breast cancer. Breast J 19: 180-188, 2013.

6. Kim R, Tan A, Lai KK, Jiang J, Wang Y, Rybicki LA and Liu X: Prognostic roles of human equilibrative transporter 1 (hENT-1) and ribonucleoside reductase subunit M1 (RRM1) in resected pancreatic cancer. Cancer 117: 3126-3134, 2011.

7. Jordheim LP, Sève P, Trédan $O$ and Dumontet C: The ribonucleotide reductase large subunit (RRM1) as a predictive factor in patients with cancer. Lancet Oncol 12: 693-702, 2011.

8. Metro G, Zheng Z, Fabi A, Schell M, Antoniani B, Mottolese M, Monteiro AN, Vici P, Lara Rivera S, Boulware D, et al: In situ protein expression of RRM1, ERCC1, and BRCA1 in metastatic breast cancer patients treated with gemcitabine-based chemotherapy. Cancer Invest 28: 172-180, 2010.

9. Ishida M, Kushima R and Okabe H: Aberrant expression of class III beta-tubulin in basal cell carcinoma of the skin. Oncol Rep 22: 733-737, 2009.

10. Lee MK, Rebhun LI and Frankfurter A: Posttranslational modification of class III beta-tubulin. Proc Natl Acad Sci USA 87: 7195-7199, 1990.

11. Aquino JB, Musolino PL, Coronel MF, Villar MJ and Setton-Avruj CP: Nerve degeneration is prevented by a single intraneural apotransferrin injection into colchicine-injured sciatic nerves in the rat. Brain Res 1117: 80-91, 2006.

12. Dumontet $C$, Isaac $S$, Souquet PJ, Bejui-Thivolet F, Pacheco $Y$, Peloux N, Frankfurter A, Luduena R and Perol M: Expression of class III beta tubulin in non-small cell lung cancer is correlated with resistance to taxane chemotherapy. Bull Cancer 92: E25-E30, 2005.

13. Ju BG, Lunyak VV, Perissi V, Garcia-Bassets I, Rose DW, Glass CK and Rosenfeld MG: A topoisomerase IIbeta-mediated dsDNA break required for regulated transcription. Science 312: 1798-1802, 2006.

14. Yarden Y and Sliwkowski MX: Untangling the ErbB signalling network. Nat Rev Mol Cell Biol 2: 127-137, 2001.

15. Czajka-Oraniec I and Simpson ER: Aromatase research and its clinical significance. Endokrynol Pol 61: 126-134, 2010.

16. Sestak I, Kealy R, Nikoloff M, Fontecha M, Forbes JF, Howell A and Cuzick J: Relationships between CYP2D6 phenotype, breast cancer and hot flushes in women at high risk of breast cancer receiving prophylactic tamoxifen: Results from the IBIS-I trial. Br J Cancer 107: 230-233, 2012.

17. Shibahara Y, Miki Y, Onodera Y, Hata S, Chan MS, Yiu CC, Loo TY, Nakamura Y, Akahira J, Ishida T, et al: Aromatase inhibitor treatment of breast cancer cells increases the expression of let-7f, a microRNA targeting CYP19A1. J Pathol 227: 357-366, 2012.

18. Fritzsche FR, Wassermann K, Jung M, Tölle A, Kristiansen I, Lein M, Johannsen M, Dietel M, Jung K and Kristiansen G: ADAM9 is highly expressed in renal cell cancer and is associated with tumour progression. BMC Cancer 8: 179, 2008.

19. Györffy B, Lanczky A, Eklund AC, Denkert C, Budczies J, Li Q, and Szallasi Z: An online survival analysis tool to rapidly assess the effect of 22,277 genes on breast cancer prognosis using microarray data of 1,809 patients. Breast Cancer Res Treat 3: 725-731, 2010.

20. Simon R: Roadmap for developing and validating therapeutically relevant genomic classifiers. J Clin Oncol 23: 7332-7341, 2005.

21. Glas AM, Floore A, Delahaye LJ, Witteveen AT, Pover RC, Bakx N, Lahti-Domenici JS, Bruinsma TJ, Warmoes MO, Bernards R, et al: Converting a breast cancer microarray signature into a high-throughput diagnostic test. BMC Genomics 7: 278, 2006.

22. Rha SY, Jeung HC, Choi YH, Yang WI, Yoo JH, Kim BS, Roh JK and Chung HC: An association between RRM1 haplotype and gemcitabine-induced neutropenia in breast cancer patients. Oncologist 12: 622-630, 2007.

23. Vici P, Fabi A, Metro G, Sergi D, Giannarelli D, Di Lauro L, Bepler G, Tomao F, Cognetti F, Conti F, et al: Phase I-II trial of prolonged gemcitabine infusion plus paclitaxel as a biweekly schedule for advanced breast cancer patients pretreated with anthracyclines. Cancer Chemother Pharmacol 67: 687-693, 2011. 
24. Davidson JD, Ma L, Flagella M, Geeganage S, Gelbert LM and Slapak CA: An increase in the expression of ribonucleotide reductase large subunit 1 is associated with gemcitabine resistance in non-small cell lung cancer cell lines. Cancer Res 64: 3761-3766, 2004.

25. Yen Y: Ribonucleotide reductase subunit one as gene therapy target: commentary re: M-Y. Cao et al: Adenovirus-mediated ribonucleotide reductase R1 gene therapy of human colon adenocarcinoma. Clin Cancer Res 9: 4304-4308, 2003.

26. Rosell R, Felip E, Taron M, Majo J, Mendez P, Sanchez-Ronco M, Queralt C, Sanchez JJ and Maestre J: Gene expression as a predictive marker of outcome in stage IIB-IIIA-IIIB non-smal cell lung cancer after induction gemcitabine-based chemotherapy followed by resectional surgery. Clin Cancer Res 10: 4215s-4219s, 2004.

27. Kim D, Jung W and Koo JS: The expression of ERCC1, RRM1, and BRCA1 in breast cancer according to the immunohistochemical phenotypes. J Korean Med Sci 26: 352-359, 2011.

28. Wang LR, Zhang GB, Chen J, Li J, Li MW, Xu N, Wang Y and Shen Tu JZ: RRM1 gene expression in peripheral blood is predictive of shorter survival in Chinese patients with advanced non-small-cell lung cancer treated by gemcitabine and platinum. J Zhejiang Univ Sci B 12: 174-179, 2011.

29. Pesta M, Kulda V, Fiala O, Safranek J, Topolcan O, Krakorova G Cerny R and Pesek M: Prognostic significance of ERCC1, RRM1 and BRCA1 in surgically-treated patients with non-small cell lung cancer. Anticancer Res 32: 5003-5010, 2012.

30. Azuma K, Sasada T, Kawahara A, Takamori S, Hattori S, Ikeda J, Itoh K, Yamada A, Kage M, Kuwano M, et al: Expression of ERCC1 and class III beta-tubulin in non-small cell lung cancer patients treated with carboplatin and paclitaxel. Lung Cancer 64: 326-333, 2009.

31. Burkhart CA, Kavallaris M and Band Horwitz S: The role of beta-tubulin isotypes in resistance to antimitotic drugs. Biochim Biophys Acta 1471: O1-O9, 2001.

32. Cheng MH, Yang YC, Wong YH, Chen TR, Lee CY, Yang CC, Chen SH, Yang IN, Yang YS, Huang HS, et al: B1, a novel topoisomerase II inhibitor, induces apoptosis and cell cycle G1 arrest in lung adenocarcinoma A549 cells. Anticancer Drugs 23: 191-199, 2012.
33. Chen S, Fariss RN, Kutty RK, Nelson R and Wiggert B Fenretinide-induced neuronal differentiation of ARPE-19 human retinal pigment epithelial cells is associated with the differential expression of Hsp70, 14-3-3, pax-6, tubulin beta-III, NSE, and bag-1 proteins. Mol Vis 12: 1355-1363, 2006

34. Carrara L, Guzzo F, Roque DM, Bellone S, Emiliano C, Sartori E, Pecorelli S, Schwartz PE, Rutherford TJ and Santin AD: Differential in vitro sensitivity to patupilone versus paclitaxel in uterine and ovarian carcinosarcoma cell lines is linked to tubulin-beta-III expression. Gynecol Oncol 125: 231-236, 2012.

35. Uppala PT, Dissmore T, Lau BH, Andacht T and Rajaram S: Selective inhibition of cell proliferation by lycopene in MCF-7 breast cancer cells in vitro: A proteomic analysis. Phytother Res 27: 595-601, 2013.

36. Zhao HY, Huang H, Hu ZH, Huang Y, Lin SX, Tian Y and Lin TY: Evaluations of biomarkers associated with sensitivity to 5-fluorouracil and taxanes for recurrent/advanced breast cancer patients treated with capecitabine-based first-line chemotherapy. Anticancer Drugs 23: 534-542, 2012.

37. Hellemans P, van Dam PA, Geyskens M, van Oosterom AT, Buytaert P and Van Marck E: Immunohistochemical study of topoisomerase II-alpha expression in primary ductal carcinoma of the breast. J Clin Pathol 48: 147-150, 1995

38. Fountzilas G, Christodoulou C, Bobos M, Kotoula V, Eleftheraki AG, Xanthakis I, Batistatou A, Pentheroudakis G, Xiros N, Papaspirou I, et al: Topoisomerase II alpha gene amplification is a favorable prognostic factor in patients with HER2-positive metastatic breast cancer treated with trastuzumab. J Transl Med 10: 212, 2012.

39. Hadfield KD and Newman WG: Pharmacogenetics of aromatase inhibitors. Pharmacogenomics 13: 699-707, 2012

40. Damodaran SE, Pradhan SC, Umamaheswaran G, Kadambari D, Reddy KS and Adithan C: Genetic polymorphisms of CYP2D6 increase the risk for recurrence of breast cancer in patients receiving tamoxifen as an adjuvant therapy. Cancer Chemother Pharmacol 70: 75-81, 2012.

41. Vilmar A, Garcia-Foncillas J, Huarriz M, Santoni-Rugiu E and Sorensen JB: RT-PCR versus immunohistochemistry for correlation and quantification of ERCC1, BRCA1, TUBB3 and RRM1 in NSCLC. Lung Cancer 75: 306-312, 2012. 